\title{
Malperfusion in acute type A aortic dissection: An update from the Nordic Consortium for Acute Type A Aortic Dissection
}

Igor Zindovic, MD, ${ }^{a}$ Tomas Gudbjartsson, MD, PhD,${ }^{b}$ Anders Ahlsson, MD, PhD, ${ }^{c}$ Simon Fuglsang, MD, ${ }^{\mathrm{d}}$ Jarmo Gunn, MD, ${ }^{\mathrm{e}}$ Emma C. Hansson, MD, PhD,${ }^{\mathrm{f}}$ Vibeke Hjortdal, MD, PhD, ${ }^{\mathrm{d}}$ Kati Järvelä, MD, PhD, ${ }^{\mathrm{g}}$ Anders Jeppsson, MD, PhD, ${ }^{\mathrm{f}}$ Ari Mennander, $\mathrm{MD}, \mathrm{PhD},{ }^{\mathrm{g}}$ Christian Olsson, $\mathrm{MD}, \mathrm{PhD},{ }^{\mathrm{h}}$ Emily Pan, BM, ${ }^{\mathrm{e}}$ Johan Sjögren, MD, PhD, ${ }^{a}$ Anders Wickbom, MD, ${ }^{c}$ Arnar Geirsson, MD, ${ }^{\text {b,i }}$ and Shahab Nozohoor, MD, $\mathrm{PhD}^{\mathrm{a}}$

\section{ABSTRACT}

Objectives: To evaluate the effect of preoperative malperfusion on 30-day and late mortality and postoperative complications using data from the Nordic Consortium for Acute Type A Aortic Dissection (ATAAD) registry.

Methods: We studied 1159 patients who underwent ATAAD surgery between January 2005 and December 2014 at 8 Nordic centers. Multivariable logistic and Cox regression analyses were performed to identify independent predictors of 30-day and late mortality.

Results: Preoperative malperfusion was identified in 381 of 1159 patients (33\%) who underwent ATAAD surgery. Thirty-day mortality was $28.9 \%$ in patients with preoperative malperfusion and $12.1 \%$ in those without. Independent predictors of 30-day mortality included any malperfusion (odds ratio, 2.76; 95\% confidence interval [CI], 1.94-3.93), cardiac malperfusion (odds ratio, 2.37; 95\% CI, 1.34-4.17), renal malperfusion (odds ratio, 2.38; 95\% CI, 1.23-4.61) and peripheral malperfusion (odds ratio, 1.95; 95\% CI, 1.26-3.01). Any malperfusion (hazard ratio, 1.72; 95\% CI, 1.21-2.43), cardiac malperfusion (hazard ratio, 1.89; 95\% CI, 1.24-2.87) and gastrointestinal malperfusion (hazard ratio, $2.25 ; 95 \% \mathrm{CI}, 1.18-4.26$ ) were predictors of late mortality. Malperfusion was associated with significantly poorer survival at 1 , 3 , and 5 years $(95.0 \% \pm 0.9 \%$ vs $88.7 \% \pm 1.9 \%, 90.1 \% \pm 1.3 \%$ vs $84.0 \% \pm 2.4 \%$, and $85.4 \% \pm 1.7 \%$ vs $80.8 \% \pm 2.7 \%$; $\log \operatorname{rank} P=.009$ ).

Conclusions: Malperfusion has a significant influence on early and late outcomes in ATAAD surgery. Management of preoperative malperfusion remains a major challenge in reducing mortality associated with surgical treatment of ATAAD. (J Thorac Cardiovasc Surg 2019;157:1324-33)

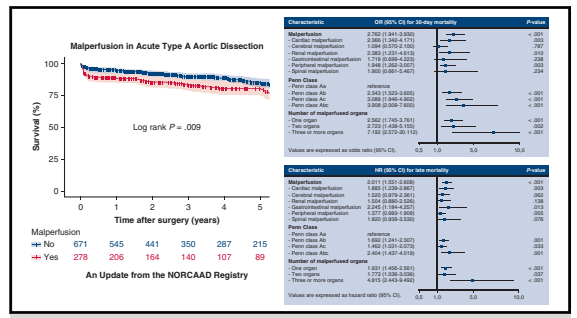

The influence of malperfusion on early and late mortality.

\section{Central Message}

The results of this multicenter study demonstrate that malperfusion has a significant influence on early and late mortality in ATAAD surgery.

\section{Perspective}

This study, based on data from the NORCAAD registry, shows that end-organ malperfusion can predict early and late mortality after surgery for ATAAD. Analysis stratified by specific organ system showed that cardiac, renal, and peripheral malperfusion was associated with poor 30-day survival, whereas cardiac and gastrointestinal malperfusion could predict late mortality.

See Commentary on page 1334.

\footnotetext{
From the a Department of Clinical Sciences and Department of Cardiothoracic Surgery, Lund University, Skane University Hospital, Lund, Sweden; ${ }^{\mathrm{b}}$ Landspitali University Hospital and Faculty of Medicine, University of Iceland, Reykjavik, Iceland; ' Department of Cardiothoracic and Vascular Surgery, Orebro University Hospital and School of Health and Medicine, Orebro University, Orebro, Sweden; ${ }^{\mathrm{d}}$ Department of Thoracic and Cardiovascular Surgery, Aarhus University Hospital, Skejby, Denmark; ${ }^{\mathrm{e}}$ Heart Center, Turku University Hospital and University of Turku, Turku, Finland; ${ }^{\mathrm{f}}$ Department of Molecular and Clinical Medicine, Institute of Medicine, Sahlgrenska Academy, University of Gothenburg, Gothenburg, Sweden; ${ }^{g}$ Heart Center, Tampere University Hospital, Tampere, Finland; ${ }^{\mathrm{h}}$ Department of Thoracic and Cardiovascular Surgery, Karolinska University Hospital, Stockholm, Sweden; and isection of Cardiac Surgery, Yale University School of Medicine, New Haven, Conn.
}

Supported in Iceland by University of Iceland Research Fund and Landspitali Research Fund and in Sweden by The Mats Kleberg Foundation.

Read at The American Association for Thoracic Surgery Aortic Symposium 2018, New York, New York, April 26-27, 2018.

Received for publication Feb 8, 2018; revisions received Sept 21, 2018; accepted for publication Oct 16, 2018; available ahead of print Dec 18, 2018.

Address for reprints: Igor Zindovic, MD, Department of Cardiothoracic Surgery, Skane University Hospital, SE-221, 85 Lund, Sweden (E-mail: igor.zindovic@ med.lu.se). $0022-5223 / \$ 36.00$

Copyright $(\subset) 2018$ by The American Association for Thoracic Surgery https://doi.org/10.1016/j.jtcvs.2018.10.134 
Abbreviations and Acronyms

ATAAD = acute type A aortic dissection

NORCAAD $=$ Nordic Consortium for Acute Type A

Aortic Dissection

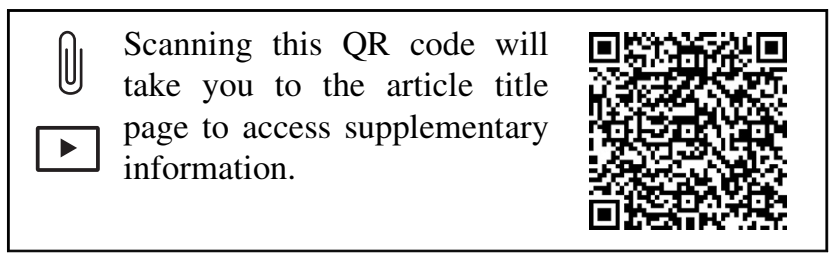

Mortality after surgery for type A aortic dissection (ATAAD) has decreased over the past decade. ${ }^{1,2}$ However, early mortality (30-day and in-hospital) remains considerable, ranging from $16 \%$ to $25 \%$ in large multicenter studies. ${ }^{1,3}$ Mortality increases by $1 \%$ to $2 \%$ per hour after symptom onset, so prompt surgical intervention is essential. ${ }^{4}$ Nevertheless, attempts to reduce mortality further are limited by complications caused by the natural history of the disease, including branch-vessel obstruction or occlusion, which can result in end-organ ischemia.

Malperfusion has been reported in $27 \%$ to $48 \%$ of patients undergoing ATAAD surgery. ${ }^{3,5-8}$ Patients most often present with iliofemoral $(13 \%)$, cerebral $(7 \%$ to $11 \%)$, or coronary malperfusion $(7 \%$ to $10 \%)$. Furthermore, preoperative malperfusion has been reported to be an independent predictor of early mortality ${ }^{1-3}$ and the Penn classification has been used as a successful model for prediction of survival in ATAAD surgery. ${ }^{6,9}$

The Nordic Consortium for Acute Type A Aortic Dissection (NORCAAD) is a database covering 1159 patients who underwent surgery for ATAAD at 1 of 8 tertiary centers in Denmark, Finland, Iceland, and Sweden from 2005 through $2014 .^{10}$

The aim of this study was to evaluate the effect of malperfusion on early and late mortality, and postoperative complications, using data from the NORCAAD registry.

\section{METHODS}

This study was approved by the institutional review board of each participating center.

\section{Study Design}

This was a multicenter, retrospective study using the NORCAAD database of patients who underwent ATAAD surgery from January 1, 2005, to December 31, 2014, at 1 of 8 Nordic centers. A total of 194 clinical variables were collected, including demographic characteristics, past medical history, preoperative medications, clinical symptoms on presentation, diagnosis methods, operative variables, complications, bleeding, blood transfusion, laboratory values, and outcome data as described elsewhere. ${ }^{10}$

\section{Definitions}

Any malperfusion was defined as the preoperative presence of any organ malperfusion according to the descriptions below. Cardiac malperfusion required ST changes, echocardiographic signs of myocardial ischemia, or creatine kinase-muscle/brain level $>75 \mathrm{mmol} / \mathrm{L}$. Loss of lateralized central neurologic function was considered to be cerebral malperfusion. Documented occlusion of the renal arteries regardless of clinical renal function constituted renal malperfusion. Gastrointestinal malperfusion was defined as mesenteric or liver ischemia. Peripheral malperfusion was defined as pulselessness or loss of sensory or motor function of upper or lower extremities, and patients with transient or permanent paraplegia were considered to have spinal malperfusion. Coma was defined as postoperative coma $>24$ hours that was not attributable to sedation.

The Penn classification has been described previously. ${ }^{6}$ Patients were categorized in 1 of 4 groups according to clinical presentation: Penn class Aa, absence of organ ischemia; Penn class Ab, localized ischemia; Penn class Ac, generalized ischemia; or Penn class Abc, localized and generalized ischemia together. Hypotensive shock was defined as systolic blood pressure $<90 \mathrm{~mm} \mathrm{Hg}$, regardless of etiology.

\section{End Points}

Primary end points were 30-day mortality, here defined as death occurring within 30 days after surgery, and late mortality, defined as all-cause mortality later than 30 days after surgery. In-hospital mortality was defined as death during index admission at the operating hospital. Secondary end points were postoperative complications.

\section{Surgical Procedures}

The decision to operate for ATAAD and specific surgical techniques were at the discretion of the surgeon responsible. As previously reported, ${ }^{10}$ standard median sternotomy, cardiopulmonary bypass, and intermittent cardioplegic arrest were routinely used. Cannulation sites varied by center, patient, and surgeon. In cases where a crossclamp was not used, resection and inspection of the aortic arch was performed under deep $\left(<20^{\circ} \mathrm{C}\right)$ or moderate $\left(21^{\circ} \mathrm{C}-32^{\circ} \mathrm{C}\right)$ hypothermic circulatory arrest, with or without the use of antegrade or retrograde cerebral perfusion. The distal surgical method depended on the location of the intimal tear and the extent of dissection. Aortic arch procedures entailed reimplantation of any supra-aortic branch. Aortic valve replacement or total root replacement was performed when the dissection involved the coronary ostia or aortic valve, or in the presence of an aortic root aneurysm. When required, the competence of the aortic valve was restored via subcommissural plication, commissural resuspension, or valvuloplasty. Concomitant procedures (eg, coronary artery bypass) were performed when required.

\section{Statistical Analysis}

Categorical data are given as proportions and continuous variables are expressed as mean \pm standard deviation. In skewed distributions, median and interquartile range are reported. Groups were compared using $\chi^{2}$ test, Student $t$ test, and Mann-Whitney $U$ test, where applicable. Linear-by-linear association was used for analyzing $P$ value for trend. Univariable and multivariable logistic regression analyses were performed to evaluate independent predictors of 30-day mortality. Due to the risk of multicollinearity, any malperfusion, malperfusion per specific organ, Penn classification, and number of malperfused organs were analyzed in separate regression models. Remaining variables constituted the baseline model and remained identical between analyses. The regression model with any malperfusion as the dependent variable constituted the default analysis. Predictors of late mortality were assessed with Cox proportional hazard regression using stepwise backward elimination, and analysis included only 30 -day survivors. Independent predictors remaining at the last step were re-evaluated using the enter method. The proportional hazards assumptions were verified with adequate diagnostic tools and no adjustments to meet the assumptions were needed for 
TABLE 1. Baseline and surgical characteristics of the study population

\begin{tabular}{|c|c|c|c|}
\hline Characteristic & No malperfusion $(n=778)$ & Malperfusion $(n=381)$ & $P$ value \\
\hline Age & $62.3 \pm 11.9$ & $60.9 \pm 10.6$ & .463 \\
\hline Male gender & $516(66.3)$ & $268(70.3)$ & .170 \\
\hline Hypertension & $392(50.4)$ & $207(54.3)$ & .207 \\
\hline History of aortic aneurysm & $84(10.8)$ & $27(7.1)$ & .044 \\
\hline Connective tissue disease & $43(5.5)$ & $13(3.4)$ & .115 \\
\hline Diabetes mellitus & $17(2.2)$ & $9(2.4)$ & .848 \\
\hline History of stroke & $30(3.9)$ & $17(4.5)$ & .623 \\
\hline Chronic kidney disease & $16(2.1)$ & $5(1.3)$ & .372 \\
\hline COPD & $48(6.2)$ & $21(5.5)$ & .657 \\
\hline History of smoking & $266(34.2)$ & $105(27.6)$ & .039 \\
\hline DeBakey type 1 & $517(66.5)$ & $329(86.4)$ & $<.001$ \\
\hline Intramural hematoma & $76(9.8)$ & $15(3.9)$ & .001 \\
\hline Hypotensive shock & $132(17.0)$ & $104(27.3)$ & $<.001$ \\
\hline Cardiac arrest & $27(3.5)$ & $30(7.9)$ & .001 \\
\hline $\begin{array}{l}\text { Malperfusion } \\
\text { Cardiac } \\
\text { Cerebral } \\
\text { Renal } \\
\text { Gastrointestinal } \\
\text { Peripheral } \\
\text { Spinal }\end{array}$ & & $\begin{array}{c}94(24.7) \\
90(23.6) \\
64(16.8) \\
36(9.5) \\
205(53.8) \\
28(7.3)\end{array}$ & \\
\hline $\begin{array}{l}\text { Penn class } \\
\qquad \mathrm{Aa} \\
\mathrm{Ab} \\
\mathrm{Ac} \\
\mathrm{Abc}\end{array}$ & $\begin{array}{l}629(80.8) \\
150(19.3)\end{array}$ & $\begin{array}{r}273(71.7) \\
46(12.1) \\
62(16.3)\end{array}$ & .002 \\
\hline $\begin{array}{l}\text { Number of malperfused organs } \\
1 \\
2 \\
\geq 3\end{array}$ & & $\begin{array}{c}287(75.3) \\
69(18.1) \\
25(6.6)\end{array}$ & \\
\hline $\begin{array}{l}\text { Proximal surgical technique } \\
\text { Supracoronary graft } \\
\text { Supracoronary graft }+ \text { AVR } \\
\text { Bentall procedure }\end{array}$ & $\begin{array}{c}548(70.4) \\
24(3.1) \\
178(22.9)\end{array}$ & $\begin{array}{l}263(69.0) \\
10(2.6) \\
90(23.6)\end{array}$ & $\begin{array}{l}.692 \\
.671 \\
.751\end{array}$ \\
\hline $\begin{array}{l}\text { Distal surgical technique } \\
\text { Ascending aorta } \\
\text { Hemiarch procedure } \\
\text { Arch procedure }\end{array}$ & $\begin{array}{c}540(69.4) \\
175(22.5) \\
46(5.9)\end{array}$ & $\begin{array}{c}275(72.2) \\
75(19.7) \\
20(5.2)\end{array}$ & $\begin{array}{l}.332 \\
.275 \\
.647\end{array}$ \\
\hline CPB time (min) & $193(160-238)$ & $196(165-238)$ & 1.000 \\
\hline Crossclamp time (min) & $87(62-131)$ & $92.5(65.3-124)$ & 1.000 \\
\hline HCA time (min) & $27(20-36)$ & $26.5(20-34)$ & 1.000 \\
\hline Lowest core temperature $\left({ }^{\circ} \mathrm{C}\right)$ & $19(18-23)$ & $19(18-22.3)$ & 1.000 \\
\hline
\end{tabular}

Values are presented as mean \pm standard deviation, $\mathrm{n}(\%)$, or median (interquartile range). COPD, Chronic obstructive pulmonary disease; $A V R$, aortic valve replacement; $C P B$, cardiopulmonary bypass; $H C A$, hypothermic circulatory arrest.

any variable. In correspondence with the multivariable logistic regression, 4 separate models were analyzed. The data were complete in $91 \%$ and $98 \%$ of possible cases in the multivariable logistic regression and Cox regression, respectively, and regression models relied on complete cases analysis. The inclusion criterion for the full regression model was $P \leq .200$ and the limit for stepwise backward elimination was $P \leq .100$. The results of logistic regression analyses are expressed as odds ratios (ORs) and those of the Cox regression analysis are expressed as hazard ratios (HRs), both with $95 \%$ confidence intervals (CIs). ORs and HRs were illustrated using forest plots. Late survival rates \pm 1 standard error were illustrated using 
TABLE 2. Early mortality and postoperative complications in the population

\begin{tabular}{|c|c|c|c|}
\hline Characteristic & No malperfusion $(n=778)$ & Malperfusion $(\mathbf{n}=\mathbf{3 8 1})$ & $P$ value \\
\hline Intraoperative mortality & $39(5.0)$ & $47(12.3)$ & $<.001$ \\
\hline 30-d mortality & $94(12.1)$ & $110(28.9)$ & $<.001$ \\
\hline In-hospital mortality & 90 (11.6) & $98(25.7)$ & $<.001$ \\
\hline Perioperative MI & $30(3.9)$ & $41(10.8)$ & $<.001$ \\
\hline Postoperative stroke & $103(13.2)$ & $74(19.4)$ & $<.001$ \\
\hline Postoperative coma & $60(7.7)$ & $46(12.1)$ & $<.004$ \\
\hline RRT & $64(8.2)$ & $66(17.2)$ & $<.001$ \\
\hline Mesenteric ischemia & $28(3.6)$ & $27(7.1)$ & .003 \\
\hline Septicemia & $62(8.0)$ & $50(13.1)$ & $<.001$ \\
\hline DSWI & $16(2.1)$ & $8(2.1)$ & .961 \\
\hline Acute limb ischemia & $11(1.4)$ & $32(8.4)$ & $<.001$ \\
\hline Surgical treatment of limb ischemia & $9(1.2)$ & $26(6.8)$ & $<.001$ \\
\hline Ventilatory support $>48 \mathrm{~h}$ & $206(26.5)$ & $148(38.8)$ & $<.001$ \\
\hline Cardiac tamponade & $94(12.1)$ & $64(16.8)$ & .001 \\
\hline Reoperation for bleeding & $142(18.3)$ & $89(23.4)$ & $<.001$ \\
\hline Length of stay in ICU (d) & $3(2-6)$ & $4(2-10)$ & $<.001$ \\
\hline Late reoperation of the aorta & $32(4.1)$ & $19(5.0)$ & .496 \\
\hline
\end{tabular}

Values are presented as $\mathrm{n}(\%)$, or as median (interquartile range). $M I$, Myocardial infarction; $R R T$, renal replacement therapy; $D S W I$, deep sternal wound infection; $I C U$, intensive care unit.

the Kaplan-Meier method, and between-group comparisons were performed using log-rank test. Statistical analysis relied on standard software (IBM-SPSS Statistics for Mac version 24.0; IBM-SPSS Inc, Armonk, NY).

\section{RESULTS}

\section{Study Population and Follow-up}

By December 2014, a total of 1159 patients had been included in the NORCAAD database. Follow-up, performed in January 2015, was $98 \%$ complete with a mean follow-up time of $3.1 \pm 2.9$ years and 137 deaths at late follow-up. Preoperative malperfusion was diagnosed in 381 patients $(32.9 \%)$.

A higher proportion of patients with no preoperative malperfusion had a history of aortic aneurysm, smoking, or intramural hematomas, whereas a higher proportion of patients with preoperative malperfusion presented with DeBakey type 1 dissections, hypotensive shock, or cardiac arrest (Table 1). Intraoperative variables were comparable between the 2 groups.

\section{Early Mortality and Postoperative Complications}

Thirty-day mortality was $28.9 \%$ in patients with malperfusion and $12.1 \%$ in those without (Table 2). Intraoperative mortality was $12.3 \%$ and $5.0 \%$, respectively. In surgery survivors, malperfusion was associated with higher rates of all the postoperative complications reported, apart from deep sternal wound infections and late reoperation of the aorta.

Table 3 shows outcomes stratified according to affected organ in patients who presented with single-organ malperfusion.
Intraoperative mortality was highest in patients with cardiac malperfusion $(18.0 \%)$, followed by those with gastrointestinal malperfusion $(15.4 \%)$ and those with cerebral malperfusion $(9.4 \%)$; however, the differences were not statistically significant (cardiac vs gastrointestinal $P=.820$, gastrointestinal vs cerebral $P=.532$, and cardiac vs cerebral $P=.187)$. The rates of 30-day mortality remained highest in patients with cardiac $(32.8 \%)$, gastrointestinal $(30.8 \%)$, and cerebral malperfusion (26.4\%) (cardiac vs gastrointestinal $P=.891$, gastrointestinal vs cerebral $P=.458$, and cardiac vs cerebral $P=.752$ ).

A higher proportion of patients with preoperative cerebral malperfusion experienced postoperative stroke, than patients with other sites of malperfusion $(30.2 \%$ vs $13.3 \% ; P=.03$ ), but they did not show a similar increase in rates of postoperative coma $(13.2 \%$ vs $9.5 \% ; P=.42)$. Renal replacement therapy was necessary in $22.7 \%$ of patients with preoperative renal malperfusion compared with $14.1 \%$ in remaining patients $(P=.54)$. Compared with patients with other sites of malperfusion, those with preoperative gastrointestinal malperfusion had the longest duration of intensive care unit stay (9.5 days [range, 3.8-14 days] vs 4 days [range, 2-7 days]) and 6.7\% of patients with single-organ malperfusion required late reoperation of the aorta. Renal malperfusion was associated with the highest rate of reoperation of the aorta $(18.1 \%)$.

Mortality and complications according to the Penn classification are demonstrated in Table E1. Thirty-day mortality for the different Penn classes was $10.0 \%, 22.8 \%$, $27.8 \%$, and $38.7 \%$ for $\mathrm{Aa}, \mathrm{Ab}, \mathrm{Ac}$, and $\mathrm{Abc}$, respectively. 
TABLE 3. Early mortality and postoperative complications in the population, according to site of preoperative malperfusion*

\begin{tabular}{|c|c|c|c|c|c|c|}
\hline Characteristic & $\begin{array}{l}\text { Cardiac } \\
(n=61)\end{array}$ & $\begin{array}{l}\text { Cerebral } \\
(\mathbf{n}=\mathbf{5 3})\end{array}$ & $\begin{array}{c}\text { Renal } \\
(n=22)\end{array}$ & $\begin{array}{c}\text { Gastrointestinal } \\
\qquad(\mathbf{n}=\mathbf{1 3})\end{array}$ & $\begin{array}{c}\text { Peripheral } \\
(n=129)\end{array}$ & $\begin{array}{l}\text { Spinal } \\
(\mathbf{n}=\mathbf{6})\end{array}$ \\
\hline Intraoperative mortality & $11(18.0)$ & $5(9.4)$ & $1(4.5)$ & $2(15.4)$ & $12(9.3)$ & $0(0)$ \\
\hline 30-d mortality & $20(32.8)$ & $14(26.4)$ & $5(22.7)$ & $4(30.8)$ & $31(24.0)$ & $2(33.3)$ \\
\hline In-hospital mortality & $17(27.9)$ & $14(26.4)$ & $5(22.7)$ & $3(23.1)$ & $26(20.2)$ & $1(16.7)$ \\
\hline Perioperative MI & $9(14.8)$ & $5(9.4)$ & $1(4.5)$ & $1(7.7)$ & $8(6.2)$ & $1(16.7)$ \\
\hline Postoperative stroke & $7(11.5)$ & $16(30.2)$ & $4(18.2)$ & $3(23.1)$ & $16(12.4)$ & $1(16.7)$ \\
\hline Postoperative coma & $4(6.6)$ & $7(13.2)$ & $3(13.6)$ & $2(15.4)$ & $11(8.5)$ & $2(33.3)$ \\
\hline RRT & $6(9.8)$ & $4(7.6)$ & $5(22.7)$ & $5(38.5)$ & $22(17.1)$ & $0(0)$ \\
\hline Mesenteric ischemia & $0(0)$ & $1(1.9)$ & $2(9.1)$ & $6(46.2)$ & $9(7.0)$ & $0(0)$ \\
\hline Septicemia & $11(18.0)$ & $5(9.4)$ & $1(4.5)$ & $4(30.8)$ & $14(10.9)$ & $0(0)$ \\
\hline DSWI & $2(3.3)$ & $3(5.7)$ & $0(0)$ & $0(0)$ & $0(0.0)$ & $0(0)$ \\
\hline Acute limb ischemia & $0(0)$ & $2(3.8)$ & $1(4.5)$ & $0(0)$ & $17(13.2)$ & $1(16.7)$ \\
\hline Surgical treatment of limb ischemia & $0(0)$ & $3(5.7)$ & $1(4.5)$ & $0(0)$ & $12(9.4)$ & $0(0)$ \\
\hline Ventilatory support $>48 \mathrm{~h}$ & $14(23.0)$ & $23(43.4)$ & $10(45.5)$ & $6(46.2)$ & $45(34.9)$ & $2(33.3)$ \\
\hline Cardiac tamponade & $9(15.7)$ & $10(18.9)$ & $6(27.3)$ & $1(7.7)$ & $25(19.4)$ & $0(0)$ \\
\hline Reoperation for bleeding & $15(24.6)$ & $11(20.8)$ & $6(27.3)$ & $2(15.4)$ & $31(24.0)$ & $2(33.3)$ \\
\hline Length of stay in ICU (d) & $3.5(2-7.5)$ & $4(2.6-8.8)$ & $3(2-7)$ & $9.5(3.8-14)$ & $4.3(2-10.1)$ & $6(3-12.5)$ \\
\hline Late reoperation of the aorta & $1(1.6)$ & $4(7.6)$ & $4(18.1)$ & $0(0)$ & $10(7.7)$ & $0(0)$ \\
\hline
\end{tabular}

Values are expressed as $\mathrm{n}(\%)$, or as median (interquartile range). $M I$, Myocardial infarction; RRT, renal replacement therapy; $D S W I$, deep sternal wound infection; $I C U$, intensive care unit. *Only patients with single-organ malperfusions are reported.

Thirty-day mortality in patients with malperfusion of 1 , 2 , or 3 or more organs was $27.6 \%, 26.1 \%$, and $52.0 \%$, respectively. Except for deep sternal wound infections, cardiac tamponade, reoperation for bleeding and late reoperation of the aorta, rates of postoperative complications increased with increasing number of affected organs (Table E2).

\section{Predictors of 30-Day Mortality}

Malperfusion-related independent predictors of 30-day mortality are shown in Figure 1. They included any malperfusion (OR, 2.76; 95\% CI, 1.94-3.93), cardiac malperfusion (OR, 2.37; 95\% CI, 1.34-4.17), renal malperfusion (OR, 2.38; 95\% CI, 1.23-4.61), peripheral malperfusion (OR, 1.95; 95\% CI, 1.26-3.01), Penn class $\mathrm{Ab}(\mathrm{OR}, 2.34$; 95\% CI, 1.52-3.61), Penn class Ac (OR, 3.09; 95\% CI, 1.95-4.90), Penn class Abc (OR, 3.91; 95\% CI, 2.01-7.60), single-organ malperfusion (OR, 2.56; 95\% CI, 1.75-3.76), double-organ malperfusion (OR, $2.72 ; 95 \% \mathrm{CI}, 1.44-5.16)$, and 3 or more malperfused organs (OR, 7.19; 95\% CI, 2.57-20.11). A full illustration of all independent predictors of 30-day mortality is presented in Table E3. Additionally, predictors of in-hospital mortality are separately presented in Table E4.

\section{Predictors of Late Mortality}

Figure 2 illustrates malperfusion-related independent predictors of late mortality in patients who survived to hospital discharge. Predictors of late mortality were any malperfusion (HR, 2.01; 95\% CI, 1.55-2.61), cardiac malperfusion (HR, 1.89; 95\% CI, 1.24-2.87), gastrointestinal malperfusion (HR, 2.25; 95\% CI, 1.18-4.26), Penn class $\mathrm{Ab}(\mathrm{HR}, 1.69 ; 95 \% \mathrm{CI}, 1.24-2.32)$, Penn class Ac (HR, 1.46; 95\% CI, 1.03-2.07), Penn class Abc (HR, $2.40 ; 95 \%$ CI, 1.44-4.02), patients with single-organ malperfusion (HR, 1.93; 95\% CI, 1.46-2.56), double-organ malperfusion (HR, 1.77; 95\% CI, 1.03-3.04), and patients with 3 or more malperfused organs (HR, 4.82; 95\% CI, 2.44-9.49). All independent predictors of late mortality are presented in Table E5.

\section{Late Survival}

Kaplan-Meier estimates of survival are demonstrated in Figure 3 and indicate that malperfusion is associated with significantly poorer survival at 1,3 , and 5 years after ATAAD surgery $(95.0 \% \pm 0.9 \%$ vs $88.7 \% \pm 1.9 \%$, $90.1 \% \pm 1.3 \%$ vs $84.0 \% \pm 2.4 \%$, and $85.4 \% \pm 1.7 \%$ vs $80.8 \% \pm 2.7 \%$, respectively; log rank $P=.009$ ). Kaplan-Meier estimates stratified per Penn class and number of malperfused organs are presented in Figures E1 and E2, and did not demonstrate any significant differences between any of the groups.

\section{DISCUSSION}

Malperfusion syndrome is a complication of aortic dissection caused by branch-vessel obstruction or occlusion, 


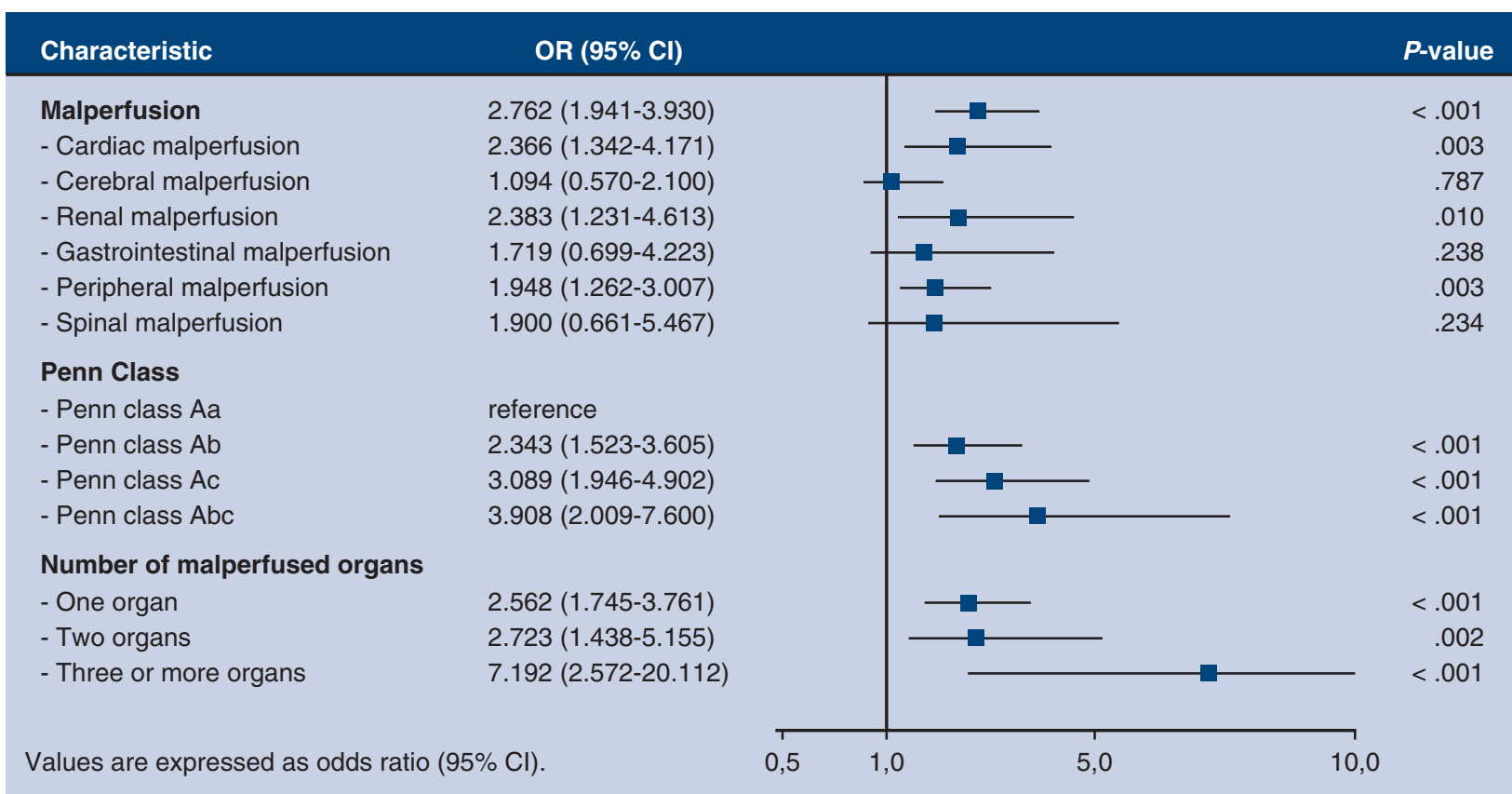

FIGURE 1. Forest plot illustrating the association between malperfusion and 30-day mortality. Any malperfusion, cardiac malperfusion, renal malperfusion, and peripheral malperfusion were independent predictors of 30-day mortality. Values are expressed as odds ratio $(O R)$ with $95 \%$ confidence interval $(C I)$.

resulting in end-organ ischemia. The severity of each aortic dissection depends on the anatomic location of the intimal tear, the extent of the dissection, and the presence of end-organ malperfusion. Despite surgical restoration of native blood flow, preoperative malperfusion remains a crucial challenge, with significant influence on morbidity and mortality. ${ }^{1-3,1}$

In the present study, patients with cardiac malperfusion had the highest risk of intraoperative mortality, possibly due to irreversible myocardial injury and inability to wean

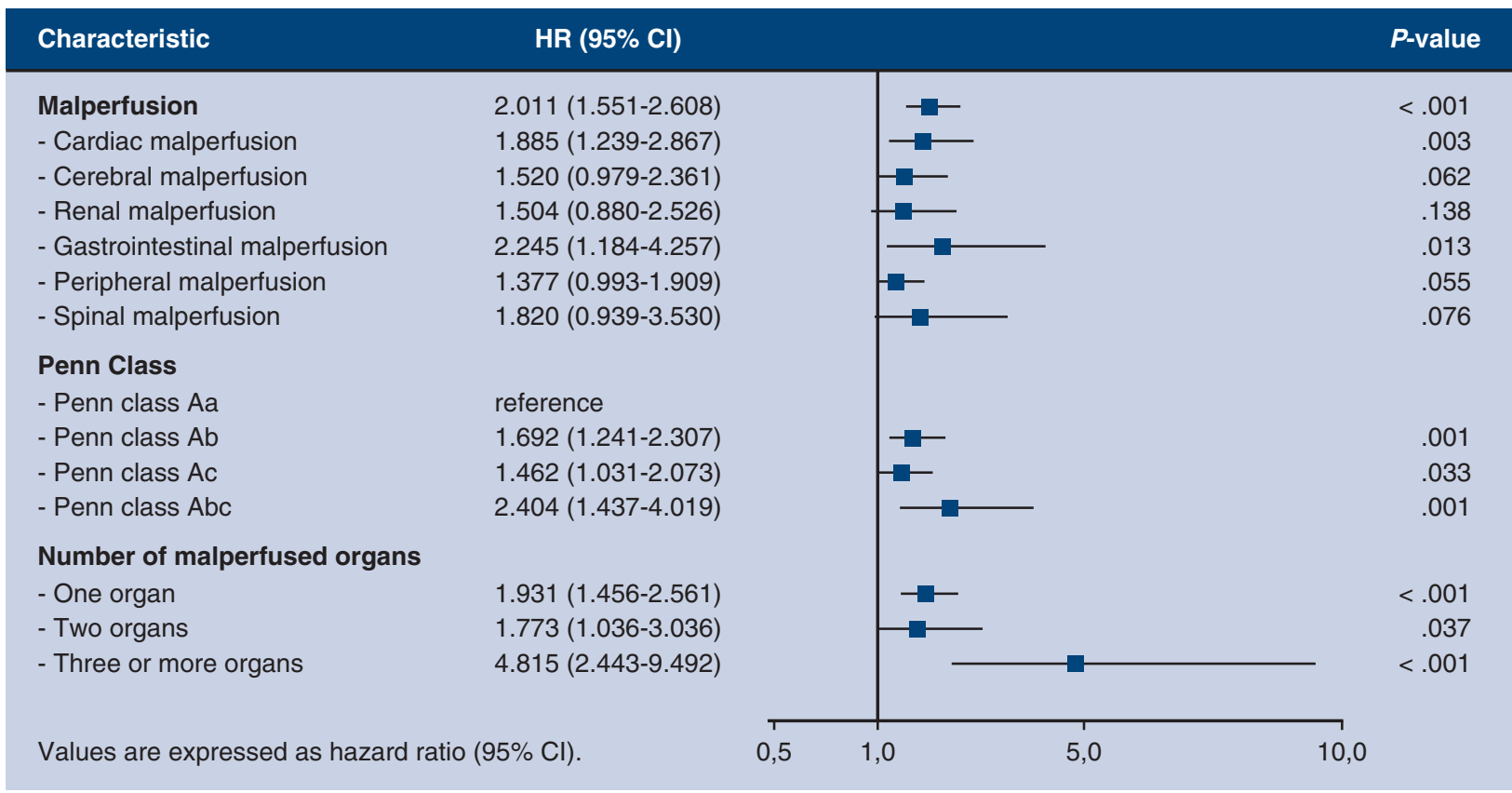

FIGURE 2. Forest plot illustrating the association between malperfusion and late mortality in 30-day survivors. Any malperfusion, cardiac malperfusion, and gastrointestinal malperfusion predicted late mortality. Values are expressed as hazard ratio $(H R)$ with $95 \%$ confidence interval $(C I)$. 


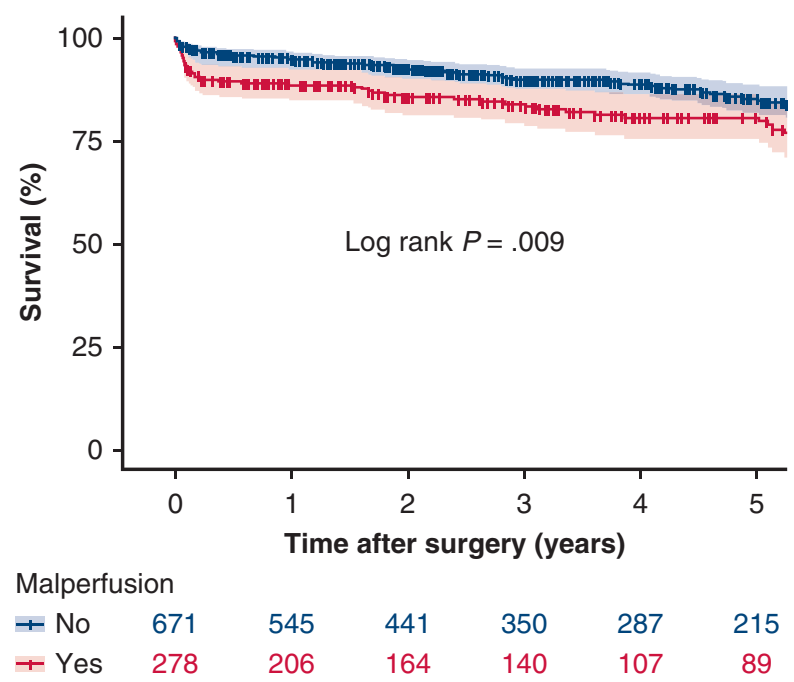

FIGURE 3. Kaplan-Meier survival curves of 30-day survivors demonstrating poorer survival in patients with preoperative malperfusion $(\log \operatorname{rank} P=.009)$

the patients off cardiopulmonary bypass. With exception of patients who died intraoperatively, the 30-day mortality rate in patients with cardiac involvement was similar to that in patients with other sites of preoperative malperfusion; however, cardiac malperfusion also predicted late mortality. Our data highlight the importance of correct diagnosis upon initial presentation. It has previously been reported that up to one-third of patients with ATAAD are mistakenly diagnosed with other conditions, most often acute coronary syndrome. ${ }^{12,13}$ After 20 minutes of myocardial ischemia death of isolated myocytes occurs, after 60 minutes most of the subendocardial myocardium is irreversibly injured, and after 3 hours more than half of the affected myocardium has transmural necrosis. ${ }^{14}$ Prompt diagnosis would not just limit the myocardial injury caused by the ischemia itself, but also the effects of reperfusion injury, including microembolization, calcium overload, hypercontacture, and overproduction of oxygen free radicals. ${ }^{15,16}$ Thus, efforts to improve diagnostic precision and reduction of the time interval between diagnosis and surgical correction are of upmost importance for further improvement of survival after ATAAD surgery.

The Penn classification, originally described by Augostides and colleagues, ${ }^{6}$ has been successful in predicting outcomes in ATAAD surgery. The present study was able to show that Penn classes Ab, Ac, and Abc were independent predictors of 30-day mortality and late mortality, but the Penn classification was not useful for group wise discrimination of 5-year survival. The inferior ability of the Penn classification to predict late outcome has previously been demonstrated by Danielsson and colleagues. ${ }^{17}$ In addition, it appears that the predictive ability of the Penn classification regarding late mortality is driven solely by malperfusion. Hypotension did not predict either early or late mortality, and preoperative cardiac arrest only predicted 30-day mortality. In our opinion, the Penn classification serves as a valuable tool, providing composite variables that enable prediction of early mortality and between-group comparisons using easily recognized clinical features.

Geirsson and colleagues ${ }^{11}$ have previously shown the influence of cerebral malperfusion on in-hospital and long-term mortality. However, in keeping with the report by Czerny and colleagues, ${ }^{3}$ describing outcomes in 2137 patients from the German Registry for Acute Aortic Dissection type A registry, cerebral malperfusion was not an independent predictor of either early or late mortality in the present study. This may be explained by the general reduction in mortality from ischemic stroke in recent years, ${ }^{18}$ and also the relatively small number of patients with cerebral malperfusion $(n=16)$ reported by Geirsson and colleagues. ${ }^{11}$ Preoperative cerebral malperfusion was associated with a twofold increase in rates of postoperative stroke $(30 \%$ vs $13 \%)$. The presence of preoperative cerebral malperfusion does not appear to correlate with increasing rates of postoperative coma, suggesting that coma might be caused by different mechanisms of cerebral injury. It has previously been shown that, apart from preoperative cerebral malperfusion, aspects of surgical technique may have an influence on postoperative neurologic function. Conzelman and colleagues ${ }^{19}$ identified operative time, cardiopulmonary bypass time, and time of circulatory arrest as independent predictors of neurologic dysfunction. Thus, one might speculate that postoperative coma, to a higher degree than stroke, might be associated with surgical management rather than preoperative cerebral malperfusion caused by dissection of the carotid arteries.

Preoperative renal malperfusion was found to be an independent predictor of 30-day mortality but was not associated with a significantly higher rate of renal replacement therapy when compared with patients with other sites of organ malperfusion. Endovascular fenestration or stenting before cardiac surgery would possibly decrease rates of postoperative organ injury, but this must be weighed against the risk of delayed surgical repair. It has been shown that $25 \%$ to $49 \%$ of patients with ATAAD die before arrival to hospital, ${ }^{20,21}$ and in a previous study on patients with malperfusion who underwent preoperative percutaneous intervention of malperfusion, $33 \%$ died after hospital admission but before open surgical correction of the aortic dissection. ${ }^{5}$ This should be interpreted in the context of the results of the present study, where patients with malperfusion had a $28.9 \%$ risk of 30 -day mortality compared with $12.1 \%$ in patients with no preoperative malperfusion. Furthermore, one must bear in mind the difficulty of preoperatively 


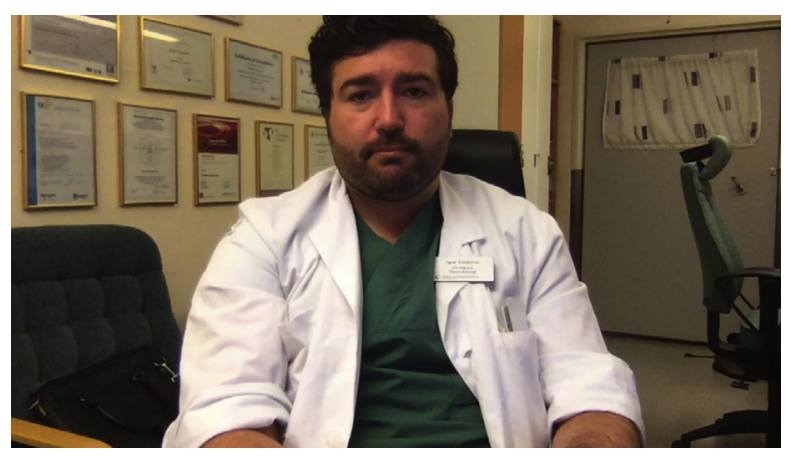

VIDEO 1. Dr Igor Zindovic, Skane University Hospital, presents the key findings of the present study. Video available at: https://www.jtcvs.org/ article/S0022-5223(18)32928-3/fulltext.

distinguishing malperfusion from irreversible organ injury and thus the risk of ineffectual intervention.

In a previous report by Di Eusanio and colleagues ${ }^{22}$ from the International Registry of Acute Aortic Dissection consisting of 2952 patients with type A dissection, mesenteric malperfusion in patients was found to carry a $63.2 \%$ risk of in-hospital mortality. However, these data also included patients with medical, endovascular, and hybrid treatment of the aortic dissection. In-hospital mortality in patients with mesenteric malperfusion who underwent ATAAD surgery was $41.7 \%$. The present study demonstrated a 30-day mortality of $30.8 \%$ in patients with gastrointestinal malperfusion. The lower mortality in our material might be explained by the low number of patients, and thus the increased risk of statistical abnormalities. The results were possibly skewed by selection bias, as patients with severe visceral ischemia might have been less likely to be considered candidates for surgery. Furthermore, our definition of gastrointestinal malperfusion included liver ischemia, which might carry a lower risk of mortality than visceral ischemia. However, Di Eusiano and colleagues ${ }^{22}$ reported outcomes in all patients with mesenteric malperfusion, and not only those with isolated mesenteric ischemia. In the same subgroup of patients, hospital mortality after medical therapy was $95 \%$. Despite this, only $69 \%$ of patients were offered surgical or endovascular treatment, most probably due to the common assumption of a dismal prognosis in the event of visceral malperfusion. It has been described that transmural intestinal infarction develops after 8 to 16 hours of total or near total ischemia. ${ }^{23}$ Due to the dramatic presentation of ATAAD and the rapidly increasing mortality, ${ }^{4}$ patients often undergo surgical treatment within hours of symptom onset. In theory, prompt restoration of the true lumen should lead to return of native mesenteric blood flow, thus preventing intestinal necrosis given that the visceral branches originate from the true lumen. However,
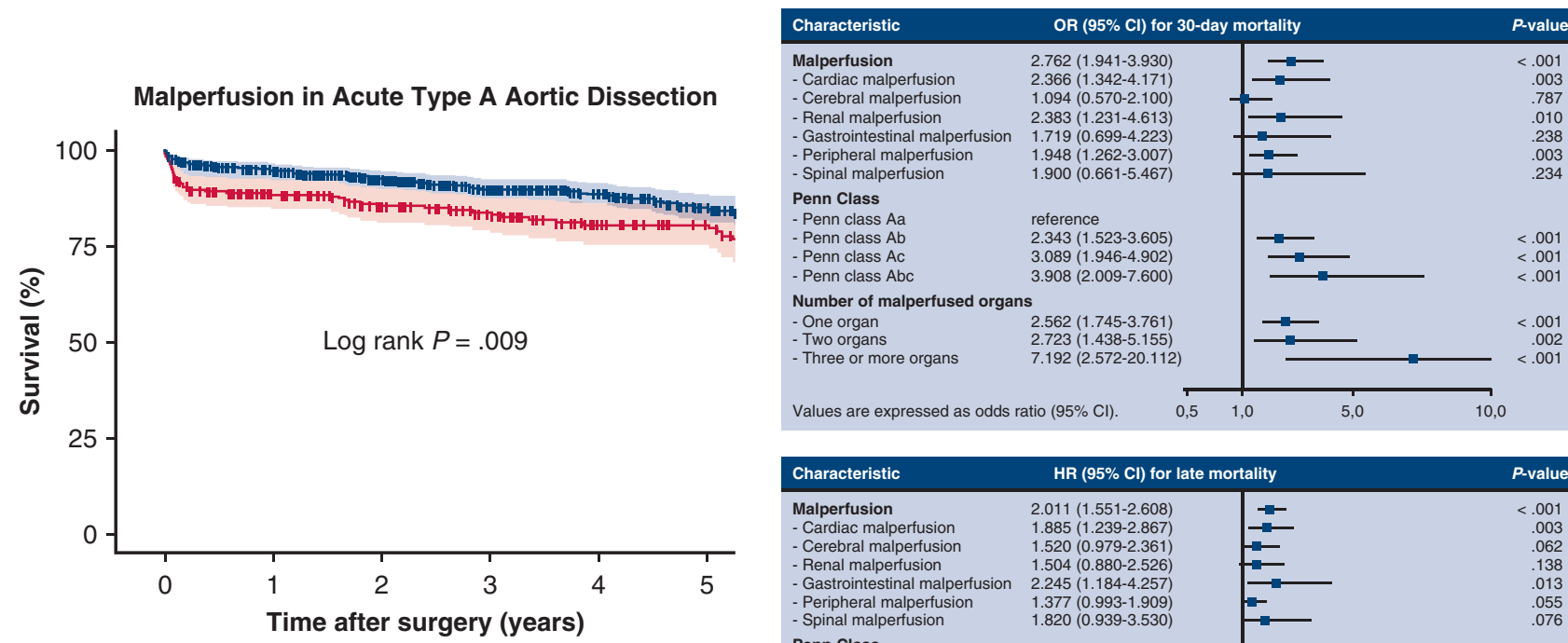

\begin{tabular}{lllllll}
\multicolumn{2}{l}{ Malperfusion } \\
+ No & 671 & 545 & 441 & 350 & 287 & 215 \\
+ Yes & 278 & 206 & 164 & 140 & 107 & 89
\end{tabular}

\begin{tabular}{|c|c|c|c|}
\hline Characteristic & HR $(95 \% \mathrm{Cl})$ for & tality & $P$-value \\
\hline Malperfusion & $2.011(1.551-2.608)$ & & $<.001$ \\
\hline $\begin{array}{l}\text { - Cardiac malperfusion } \\
\text { - Cerebral malperfusion }\end{array}$ & $\begin{array}{l}1.885(1.239-2.867) \\
1.520 \\
0.979-2361)\end{array}$ & $\rightarrow-$ & .003 \\
\hline $\begin{array}{l}\text {-Cerebral malperfusion } \\
\text { - Renal malperfusion }\end{array}$ & $\begin{array}{l}1.520(0.979-2.361) \\
1.504(0.880-2526)\end{array}$ & $E$ & .062 \\
\hline - Gastrointestinal malperfusion & $2.245(1.184-4.257)$ & $\rightarrow$ & . .138 \\
\hline - Peripheral malperfusion & 1.377 (0.993-1.909) & & .055 \\
\hline - Spinal malperfusion & $1.820(0.939-3.530)$ & & .076 \\
\hline Penn Class & & & \\
\hline - Penn class Aa & reference & & \\
\hline - Penn class Ab & $1.692(1.241-2.307)$ & $=$ & .001 \\
\hline $\begin{array}{l}\text {-Penn class Ac } \\
\text { - Penn nlass Abc }\end{array}$ & $\begin{array}{l}1.462(1.031-2.073) \\
2.404(1.437-4.019)\end{array}$ & $=$ & .033 \\
\hline Number of malperfused orgar & & & \\
\hline - One organ & $1.931(1.456-2.561)$ & $\rightarrow$ & \\
\hline - Two organs & $1.773(1.036-3.3036)$ & & .037 \\
\hline - Three or more organs & $4.815(2.443-9.492)$ & & $<.001$ \\
\hline & & & \\
\hline
\end{tabular}

FIGURE 4. Preoperative end-organ malperfusion has a negative influence on short-term and late survival in patients undergoing surgery for acute type A aortic dissection. Values are expressed as odds ratio $(O R)$ or hazard ratio $(H R)$ with $95 \%$ confidence interval $(C I)$. NORCAAD, Nordic Consortium for Acute Type A Aortic Dissection. 
persistent false lumen perfusion, and consequently potential true lumen compression, is common and is associated with higher mortality and an increased risk of complications. ${ }^{24}$ In the present study, gastrointestinal malperfusion was an independent predictor of late mortality, possibly serving as a surrogate for dissection of the distal aorta and false lumen patency. Thus, the option of surgery using the frozen elephant trunk technique and subsequent endovascular restoration of end-organ perfusion is appealing. It has been shown that extensive aortic repair in ATAAD surgery is associated with impaired short-term survival ${ }^{25}$ and surgery for ATAAD performed by nonaortic surgeons has been reported to be an independent predictor of poor surgical outcome. ${ }^{26}$ Surgery for ATAAD is an emergency operation that is often performed by an on-call consultant and not necessarily a surgeon who specializes in aortic surgery. In this setting, a less extensive repair should be advocated. However, in the hands of an experienced aortic surgeon, the benefits of eliminating false lumen patency might outweigh the risks of extensive surgery and the frozen elephant trunk technique might be considered. This study showed acceptable 30-day mortality in selected patients with preoperative gastrointestinal malperfusion, and the $95 \%$ in-hospital mortality for medically treated patients previously reported by Di Eusiano and colleagues ${ }^{22}$ might possibly favor surgery despite its high risk in this category of patients.

The limitations of this study include its retrospective design. The multicenter nature of the registry has limited the possibility of additional review of patient charts, but has enabled us to perform among the largest studies on malperfusion in ATAAD surgery. Still, there is a risk of analyses and results being underpowered and influenced by unreported confounders. Furthermore, patients are often diagnosed with ATAAD without a full preoperative investigation, which might lead to organ malperfusion being overlooked. Dynamic malperfusion might be missed on computed tomography and malperfusion may occur after the point of imaging. In addition, the diagnosis of organ malperfusion in our registry does not rely on any standardized definitions and we have not distinguished preoperative malperfusion from manifest organ injury, which might influence the interpretation of our results. The current study had no information on causes of death and therefore one cannot with any certainty assume causality between malperfusion and its effect on late mortality in particular.

\section{CONCLUSIONS}

As described in Video 1 and depicted in Figure 4, the current study shows that preoperative malperfusion has a significant effect on early and late mortality in ATAAD surgery. Cardiac malperfusion was found to be associated with the highest rate of intraoperative mortality.
Preoperative malperfusion remains a major risk factor for mortality associated with the surgical treatment of ATAAD, and the optimal management of end-organ malperfusion is yet to be fully investigated.

\section{Conflict of Interest Statement}

Authors have nothing to disclose with regard to commercial support.

\section{References}

1. Geirsson A, Ahlsson A, Franco-Cereceda A, Fuglsang S, Gunn J, Hansson EC, et al. Hospital volumes and later year of operation correlates with better outcomes in acute type A aortic dissection. Eur J Cardiothorac Surg. 2018;53: 276-81.

2. Berretta P, Patel HJ, Gleason TG, Sundt TM, Myrmel T, Desai N, et al. IRAD experience on surgical type A acute dissection patients: results and predictors of mortality. Ann Cardiothorac Surg. 2016;5:346-51.

3. Czerny M, Schoenhoff F, Etz C, Englberger L, Khaladj N, Zierer A, et al. The impact of pre-operative malperfusion on outcome in acute type a aortic dissection: results from the GERAADA registry. J Am Coll Cardiol. 2015;65: 2628-35.

4. Bonser RS, Ranasinghe AM, Loubani M, Evans JD, Thalji NM, Bachet JE, et al. Evidence, lack of evidence, controversy, and debate in the provision and performance of the surgery of acute type A aortic dissection. J Am Coll Cardiol. 2011;58:2455-74.

5. Patel HJ, Williams DM, Dasika NL, Suzuki Y, Deeb GM. Operative delay for peripheral malperfusion syndrome in acute type A aortic dissection: a long-term analysis. J Thorac Cardiovasc Surg. 2008;135:1288-95.

6. Augoustides JG, Geirsson A, Szeto WY, Walsh EK, Cornelius B, Pochettino A, et al. Observational study of mortality risk stratification by ischemic presentation in patients with acute type A aortic dissection: the Penn classification. Nat Clin Pract Cardiovasc Med. 2009;6:140-6.

7. Yagdi T, Atay Y, Engin C, Mahmudov R, Tetik O, Iyem H, et al. Impact of organ malperfusion on mortality and morbidity in acute type A aortic dissections. $J$ Card Surg. 2006;21:363-9.

8. Narayan P, Rogers CA, Benedetto U, Caputo M, Angelini GD, Bryan AJ. Malperfusion rather than merely timing of operative repair determines early and late outcome in type A aortic dissection. J Thorac Cardiovasc Surg. 2017; 154:81-6.

9. Olsson C, Hillebrant CG, Liska J, Lockowandt U, Eriksson P, FrancoCereceda A. Mortality in acute type A aortic dissection: validation of the Penn classification. Ann Thorac Surg. 2011;92:1376-82.

10. Geirsson A, Ahlsson A, Franco-Cereceda A, Fuglsang S, Gunn J, Hansson EC, et al. The Nordic Consortium for Acute type A Aortic Dissection (NORCAAD): objectives and design. Scand Cardiovasc J. 2016;1-7.

11. Geirsson A, Szeto WY, Pochettino A, McGarvey ML, Keane MG, Woo YJ, et al. Significance of malperfusion syndromes prior to contemporary surgical repair for acute type A dissection: outcomes and need for additional revascularizations. Eur J Cardiothorac Surg. 2007;32:255-62.

12. Hansson EC, Dellborg M, Lepore V, Jeppsson A. Prevalence, indications and appropriateness of antiplatelet therapy in patients operated for acute aortic dissection: associations with bleeding complications and mortality. Heart. 2013;99:116-21.

13. Lentini S, Perrotta S. Aortic dissection with concomitant acute myocardial infarction: from diagnosis to management. J Emerg Trauma Shock. 2011;4:273-8.

14. Reimer KA, Lowe JE, Rasmussen MM, Jennings RB. The wavefront phenomenon of ischemic cell death. 1. Myocardial infarct size vs duration of coronary occlusion in dogs. Circulation. 1977;56:786-94.

15. Jennings RB, Ganote CE. Structural changes in myocardium during acute ischemia. Circ Res. 1974;35:156-72.

16. Bainey KR, Armstrong PW. Clinical perspectives on reperfusion injury in acute myocardial infarction. Am Heart J. 2014;167:637-45.

17. Danielsson E, Zindovic I, Bjursten H, Ingemansson R, Nozohoor S. Generalized ischaemia in type A aortic dissections predicts early surgical outcomes only Interact Cardiovasc Thorac Surg. 2015;21:822-9.

18. Vaartjes I, O'Flaherty M, Capewell S, Kappelle J, Bots M. Remarkable decline in ischemic stroke mortality is not matched by changes in incidence. Stroke. 2013; 44:591-7. 
19. Conzelmann LO, Hoffmann I, Blettner M, Kallenbach K, Karck M, Dapunt O, et al. Analysis of risk factors for neurological dysfunction in patients with acute aortic dissection type A: data from the German Registry for Acute Aortic Dissection type A (GERAADA). Eur J Cardiothorac Surg. 2012;42:557-65.

20. Howard DP, Banerjee A, Fairhead JF, Perkins J, Silver LE, Rothwell PM, et al. Population-based study of incidence and outcome of acute aortic dissection and premorbid risk factor control: 10-year results from the Oxford Vascular Study. Circulation. 2013;127:2031-7.

21. Melvinsdottir IH, Lund SH, Agnarsson BA, Sigvaldason K, Gudbjartsson T, Geirsson A. The incidence and mortality of acute thoracic aortic dissection: results from a whole nation study. Eur J Cardiothorac Surg. 2016;50:1111-7.

22. Di Eusanio M, Trimarchi S, Patel HJ, Hutchison S, Suzuki T, Peterson MD, et al. Clinical presentation, management, and short-term outcome of patients with type A acute dissection complicated by mesenteric malperfusion: observations from the International Registry of Acute Aortic Dissection. J Thorac Cardiovasc Surg. 2013;145:385-90.e1.
23. Haglund U, Bergqvist D. Intestinal ischemia-the basics. Langenbecks Arch Surg. 1999;384:233-8.

24. Evangelista A, Salas A, Ribera A, Ferreira-Gonzalez I, Cuellar H, Pineda V, et al. Long-term outcome of aortic dissection with patent false lumen: predictive role of entry tear size and location. Circulation. 2012; 125:3133-41.

25. Rylski B, Beyersdorf F, Kari FA, Schlosser J, Blanke P, Siepe M. Acute type A aortic dissection extending beyond ascending aorta: limited or extensive distal repair. J Thorac Cardiovasc Surg. 2014;148:949-54.

26. Buonocore M, Amarelli C, Scardone M, Caiazzo A, Petrone G, Majello L, et al Cerebral perfusion issues in acute type A aortic dissection without preoperative malperfusion: how do surgical factors affect outcomes? Eur J Cardiothorac Surg. 2016;50:652-9.

Key Words: aorta, dissection, malperfusion 


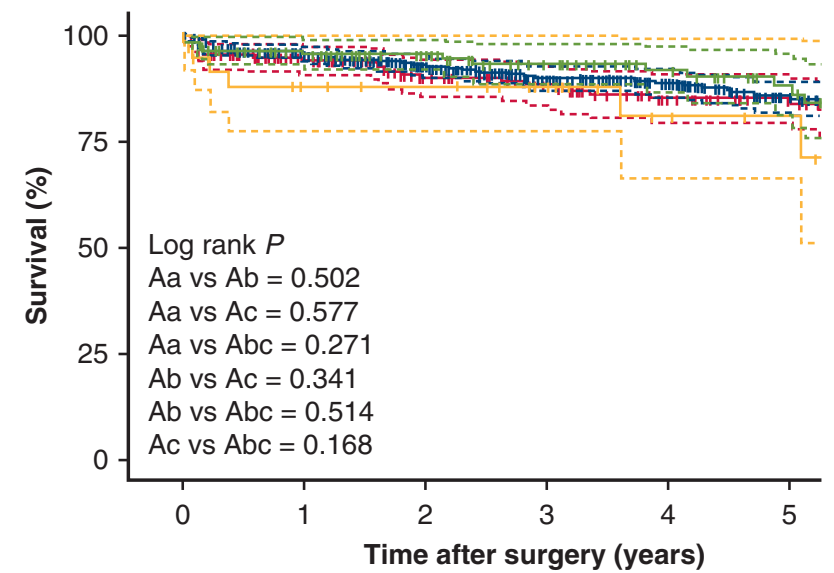

Penn class

$\begin{array}{ccccccc}+\mathrm{Aa} & 551 & 449 & 362 & 290 & 237 & 178 \\ +\mathrm{Ab} & 206 & 164 & 126 & 110 & 88 & 73 \\ +\mathrm{Ac} & 138 & 113 & 94 & 72 & 58 & 45 \\ +\mathrm{Abc} & 38 & 25 & 23 & 18 & 11 & 8\end{array}$

FIGURE E1. Kaplan-Meier survival curves of 30-day survivors plotted by Penn class. There were no significant differences in late survival between the different Penn classes.

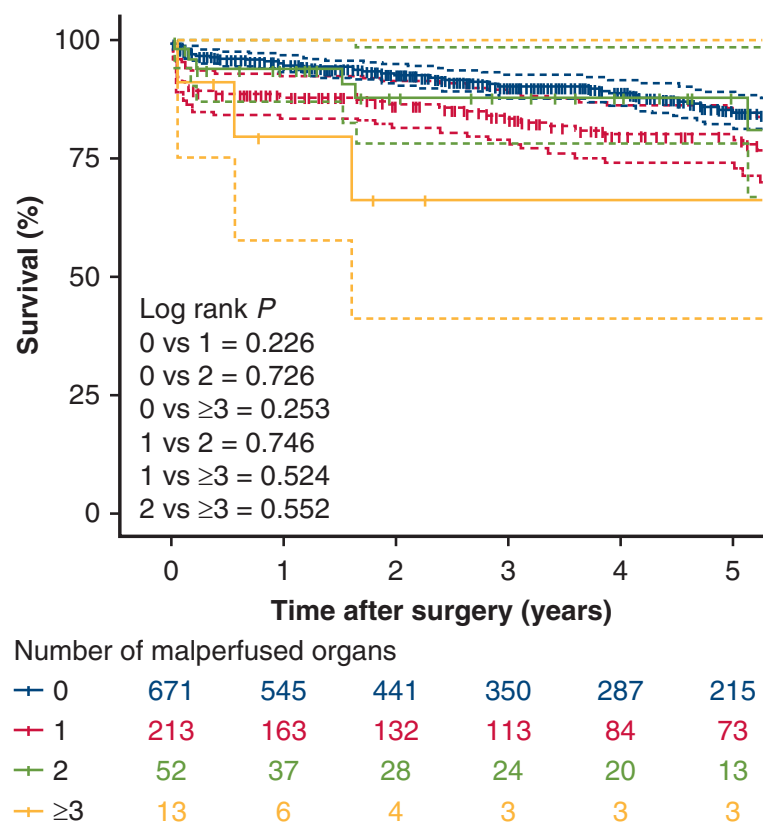

FIGURE E2. Kaplan-Meier survival curves of 30-day survivors plotted number of malperfused organs. There were no significant differences in late survival between the groups. 
TABLE E1. Early mortality and postoperative complications in the population, according to Penn class

\begin{tabular}{|c|c|c|c|c|c|}
\hline Characteristic & Aa $(n=629)$ & $\operatorname{Ab}(n=273)$ & $\operatorname{Ac}(n=196)$ & $\operatorname{Abc}(n=62)$ & $P$ value \\
\hline Intraoperative mortality & $24(3.8)$ & $25(9.2)$ & $23(11.8)$ & $13(21.0)$ & $<.001$ \\
\hline 30-d mortality & $63(10.0)$ & $62(22.8)$ & $54(27.8)$ & $24(38.7)$ & $<.001$ \\
\hline In-hospital mortality & $60(9.6)$ & $54(19.9)$ & $51(26.3)$ & $22(35.5)$ & $<.001$ \\
\hline Perioperative MI & $21(3.4)$ & $27(10.1)$ & $13(7.1)$ & $10(18.2)$ & $<.001$ \\
\hline Postoperative stroke & $72(11.7)$ & 45 (16.7) & 39 (20.9) & $21(38.9)$ & $<.001$ \\
\hline Postoperative coma & $44(7.8)$ & $28(11.7)$ & $22(14.0)$ & $10(24.4)$ & $<.001$ \\
\hline RRT & $50(8.1)$ & $46(17.2)$ & $23(12.4)$ & $11(20.8)$ & .001 \\
\hline Mesenteric ischemia & $21(3.7)$ & $21(8.8)$ & $8(5.1)$ & $5(10.9)$ & .028 \\
\hline Septicemia & 49 (7.9) & $37(13.8)$ & $18(9.6)$ & $8(15.1)$ & .054 \\
\hline DSWI & $16(2.6)$ & $3(1.1)$ & $6(3.3)$ & $1(2.0)$ & .964 \\
\hline Acute limb ischemia & $10(1.6)$ & $24(9.0)$ & $2(1.1)$ & $7(13.2)$ & .001 \\
\hline Surgical treatment of limb ischemia & $9(1.6)$ & $19(8.0)$ & $1(0.6)$ & $6(14.6)$ & .003 \\
\hline Ventilatory support $>48 \mathrm{~h}$ & $147(24.0)$ & $100(37.7)$ & $74(40.4)$ & $33(62.3)$ & $<.001$ \\
\hline Cardiac tamponade & $70(11.3)$ & $46(17.2)$ & $34(18.2)$ & $10(18.9)$ & .004 \\
\hline Reoperation for bleeding & $106(17.1)$ & $71(26.7)$ & $45(24.2)$ & $9(16.4)$ & .054 \\
\hline Length of stay in ICU (d) & $3(2-6)$ & $4(2-9.5)$ & $4(2-7)$ & $5(2.5-10)$ & $<.001$ \\
\hline Late reoperation of the aorta & $27(4.3)$ & $16(5.9)$ & $6(3.1)$ & $2(3.2)$ & 608 \\
\hline
\end{tabular}

Values are expressed as $\mathrm{n}(\%)$, or as median (interquartile range). $M I$, Myocardial infarction; $R R T$, renal replacement therapy; $D S W I$, deep sternal wound infection; $I C U$, intensive care unit.

TABLE E2. Early mortality and postoperative complications in the population, according to the number of malperfused organs

\begin{tabular}{|c|c|c|c|c|}
\hline Characteristic & $1(n=284)$ & $2(n=69)$ & $\geq 3(\mathbf{n}=25)$ & $P$ value \\
\hline Intraoperative mortality & $32(11.1)$ & $9(13.0)$ & $6(24.0)$ & $<.001$ \\
\hline 30-d mortality & 79 (27.6) & $18(26.1)$ & $13(52.0)$ & $<.001$ \\
\hline In-hospital mortality & $69(24.1)$ & $17(24.6)$ & $12(48.0)$ & $<.001$ \\
\hline Perioperative MI & $26(9.1)$ & $10(14.5)$ & $5(20.0)$ & $<.001$ \\
\hline Postoperative stroke & $47(16.4)$ & $18(26.1)$ & $9(36.0)$ & $<.001$ \\
\hline Postoperative coma & $30(10.5)$ & $9(13.0)$ & $7(28.0)$ & $<.001$ \\
\hline RRT & $42(14.6)$ & $19(27.4)$ & $5(20.0)$ & $<.001$ \\
\hline Mesenteric ischemia & $18(6.3)$ & $6(8.7)$ & $3(12.0)$ & .001 \\
\hline Septicemia & $35(12.2)$ & $9(13.0)$ & $6(24.0)$ & .001 \\
\hline DSWI & $5(1.7)$ & $3(4.3)$ & $0(0)$ & .272 \\
\hline Acute limb ischemia & $22(7.7)$ & $5(7.2)$ & $5(20.0)$ & $<.001$ \\
\hline Surgical treatment of limb ischemia & $17(5.8)$ & $7(10.1)$ & $2(8.0)$ & $<.001$ \\
\hline Ventilatory support $>48 \mathrm{~h}$ & $101(35.2)$ & $36(52.2)$ & $11(44.0)$ & $<.001$ \\
\hline Cardiac tamponade & $52(18.1)$ & $11(15.9)$ & $1(4.0)$ & .215 \\
\hline Reoperation for bleeding & $69(24.0)$ & 17 (24.6) & $3(12.0)$ & .120 \\
\hline Length of stay in ICU (d) & $4(2-9.3)$ & $6(3-13)$ & $4(1-8)$ & $<.001$ \\
\hline Late reoperation of the aorta & $15(5.2)$ & $2(2.9)$ & $2(8.0)$ & .541 \\
\hline
\end{tabular}

Values are presented as $\mathrm{n}(\%)$, or as median (interquartile range). $M I$, Myocardial infarction; $R R T$, renal replacement therapy; $D S W I$, deep sternal wound infection; $I C U$, intensive care unit. 
TABLE E3. Univariable and multivariable logistic regression analysis for predictors of 30-day mortality

\begin{tabular}{|c|c|c|c|c|}
\hline Characteristic & Univariable analysis & $P$ value & Multivariable analysis & $P$ value \\
\hline Age per year increment & $1.014(1.001-1.027)$ & .040 & & \\
\hline Male gender & $0.978(0.709-1.350)$ & .892 & & \\
\hline Hypertension & $1.452(1.068-1.973)$ & .017 & & \\
\hline History of aortic aneurysm & $0.960(0.571-1.613)$ & .878 & & \\
\hline Connective tissue disease & $0.558(0.236-1.322)$ & .185 & & \\
\hline Diabetes mellitus & $3.560(1.610-7.871)$ & .002 & $3.650(1.385-9.618)$ & .009 \\
\hline History of stroke & $1.450(0.725-2.900)$ & .293 & & \\
\hline Chronic kidney disease & $1.470(0.532-4.059)$ & .457 & & \\
\hline COPD & $2.328(1.369-3.957)$ & .002 & $2.627(1.411-4.888)$ & .002 \\
\hline DeBakey type $1 *$ & $1.414(0.981-2.038)$ & .063 & & \\
\hline Intramural hematoma & $0.837(0.464-1.512)$ & .556 & & \\
\hline Hypotensive shock & $2.151(1.534-3.016)$ & $<.001$ & & \\
\hline Cardiac arrest & $3.431(1.974-5.962)$ & $<.001$ & $3.242(1.740-6.038)$ & $<.001$ \\
\hline Malperfusion & $2.956(2.170-4.027)$ & $<.001$ & $2.762(1.941-3.930)$ & $<.001$ \\
\hline Cardiac & $3.324(2.122-5.207)$ & $<.001$ & $2.366(1.342-4.171)$ & .003 \\
\hline Cerebral & $1.661(1.012-2.728)$ & .045 & $1.094(0.570-2.100)$ & .787 \\
\hline Renal & $3.278(1.937-5.546)$ & $<.001$ & $2.383(1.231-4.613)$ & .010 \\
\hline Gastrointestinal & $3.278(1.657-6.485)$ & .001 & $1.719(0.699-4.223)$ & .238 \\
\hline Peripheral & $1.828(1.277-2.618)$ & .001 & $1.948(1.262-3.007)$ & .003 \\
\hline Spinal & $2.489(1.130-5.482)$ & .024 & $1.900(0.661-5.467)$ & .234 \\
\hline \multicolumn{5}{|l|}{ Penn class } \\
\hline $\mathrm{Aa}$ & reference & & reference & \\
\hline $\mathrm{Ab}$ & $2.692(1.773-3.818)$ & $<.001$ & $2.343(1.523-3.605)$ & $<.001$ \\
\hline Ac & $3.399(2.263-5.105)$ & $<.001$ & 3.089 (1.946-4.902) & $<.001$ \\
\hline $\mathrm{Abc}$ & $5.566(3.139-9.868)$ & $<.001$ & $3.908(2.009-7.600)$ & $<.001$ \\
\hline \multicolumn{5}{|l|}{ Number of malperfused organs } \\
\hline 1 & $2.769(1.976-3.879)$ & $<.001$ & $2.562(1.745-3.761)$ & $<.001$ \\
\hline 2 & $2.561(1.435-4.569)$ & .001 & $2.723(1.438-5.155)$ & .002 \\
\hline$\geq 3$ & $7.860(3.484-17.734)$ & $<.001$ & $7.192(2.572-20.112)$ & $<.001$ \\
\hline
\end{tabular}

Proximal surgical technique

Supracoronary graft

reference

Supracoronary graft + AVR

$3.399(1.636-7.062) \quad .001$

Bentall procedure

$1.934(1.368-2.734) \quad<.001$

Distal surgical technique

Ascending aorta reference

Hemiarch procedure $\quad 0.839(0.560-1.255) \quad 392$

Arch procedure

$2.083(1.184-3.662) \quad .011$

$\mathrm{CPB}$ time per minute increment

$1.007(1.005-1.009) \quad<.001$

$1.007(1.004-1.009)$

$<.001$

Crossclamp time per minute increment

$1.007(1.004-1.010) \quad<.001$

Lowest core temperature per ${ }^{\circ} \mathrm{C}$ increment

$1.007(0.973-1.041)$

.699

Values are presented as odds ratio ( $95 \%$ confidence interval). $C O P D$, Chronic obstructive pulmonary disease; $A V R$, aortic valve replacement; $C P B$, cardiopulmonary bypass. *Reference: Type 2. 
TABLE E4. Univariable and multivariable logistic regression analysis for predictors of in-hospital mortality

\begin{tabular}{|c|c|c|c|c|}
\hline Characteristic & Univariable analysis & $P$ value & Multivariable analysis & $P$ value \\
\hline Age per year increment & $1.011(0.997-1.024)$ & .126 & & \\
\hline Male gender & $1.032(0.735-1.449)$ & .855 & & \\
\hline Hypertension & $1.346(0.979-1.851)$ & .067 & & \\
\hline History of aortic aneurysm & $1.029(0.604-1.752)$ & .917 & & \\
\hline Connective tissue disease & $1.589(0.670-3.770)$ & .293 & & \\
\hline Diabetes mellitus & $3.332(1.488-7.464)$ & .003 & & \\
\hline History of stroke & $1.408(0.688-2.885)$ & .349 & & \\
\hline Chronic kidney disease & $1.289(0.426-3.899)$ & .653 & & \\
\hline COPD & $2.572(1.493-4.432)$ & .001 & $3.568(1.896-6.717)$ & $<.001$ \\
\hline DeBakey type $1^{*}$ & $1.244(0.857-1.807)$ & .250 & & \\
\hline Intramural hematoma & $0.612(0.311-1.205)$ & .155 & & \\
\hline Hypotensive shock & $2.366(1.674-3.346)$ & $<.001$ & & \\
\hline Cardiac arrest & $3.525(2.016-6.162)$ & $<.001$ & $3.717(1.962-7.043)$ & $<.001$ \\
\hline Malperfusion & $2.604(1.890-3.587)$ & $<.001$ & $2.291(1.583-3.316)$ & $<.001$ \\
\hline Cardiac & $3.259(2.059-5.159)$ & $<.001$ & $2.096(1.159-3.791)$ & .014 \\
\hline Cerebral & $1.673(1.002-2.794)$ & .045 & $1.111(0.558-2.211)$ & .765 \\
\hline Renal & $3.590(2.099-6.140)$ & $<.001$ & $3.132(1.608-6.102)$ & .001 \\
\hline Gastrointestinal & $2.830(1.404-5.702)$ & .004 & $1.623(0.576-4.578)$ & .360 \\
\hline Peripheral & $1.643(1.129-2.390)$ & .009 & $1.652(1.043-2.615)$ & .032 \\
\hline Spinal & $1.950(0.845-4.501)$ & .118 & $1.366(0.417-4.471)$ & .606 \\
\hline \multicolumn{5}{|l|}{ Penn class } \\
\hline $\mathrm{Aa}$ & reference & & reference & \\
\hline $\mathrm{Ab}$ & $2.244(1.499-3.359)$ & $<.001$ & $1.914(1.208-3.034)$ & .006 \\
\hline Ac & $3.340(2.202-5.065)$ & $<.001$ & $2.914(1.812-4.685)$ & $<.001$ \\
\hline $\mathrm{Abc}$ & $5.078(2.831-9.111)$ & $<.001$ & $3.376(1.701-6.699)$ & .001 \\
\hline \multicolumn{5}{|l|}{ Number of malperfused organs } \\
\hline 1 & $2.372(1.667-3.374)$ & $<.001$ & $2.083(1.385-3.132)$ & $<.001$ \\
\hline 2 & $2.465(1.366-4.449)$ & .003 & $2.533(1.311-4.894)$ & .006 \\
\hline$\geq 3$ & $6.959(3.080-15.725)$ & $<.001$ & $6.482(2.169-19.366)$ & .001 \\
\hline \multicolumn{5}{|l|}{ Proximal surgical technique } \\
\hline Supracoronary graft & reference & & reference & \\
\hline Supracoronary graft + AVR & $2.797(1.262-6.197)$ & .011 & & \\
\hline Bentall procedure & $2.486(1.745-3.541)$ & $<.001$ & $1.859(1.217-2.840)$ & .004 \\
\hline \multicolumn{5}{|l|}{ Distal surgical technique } \\
\hline Ascending aorta & reference & & & \\
\hline Hemiarch procedure & $0.807(0.525-1.239)$ & .327 & & \\
\hline Arch procedure & $2.377(1.345-4.199)$ & .003 & & \\
\hline CPB time per minute increment & $1.007(1.005-1.009)$ & $<.001$ & $1.008(1.006-1.010)$ & $<.001$ \\
\hline Crossclamp time per minute increment & $1.007(1.004-1.010)$ & $<.001$ & & \\
\hline Lowest core temperature per ${ }^{\circ} \mathrm{C}$ increment & $0.995(0.960-1.031)$ & .770 & & \\
\hline
\end{tabular}

Values are presented as odds ratio ( $95 \%$ confidence interval). Any malperfusion, malperfusion per specific organ, Penn classification, and number of malperfused organs were analyzed in separate regression models. COPD, Chronic obstructive pulmonary disease; $A V R$, aortic valve replacement; $C P B$, cardiopulmonary bypass. *Reference: Type 2. 
TABLE E5. Univariable and multivariable Cox regression analysis for predictors of late mortality

\begin{tabular}{|c|c|c|c|c|}
\hline Characteristic & Univariable analysis & $P$ value & Multivariable analysis & $P$ value \\
\hline Age per year increment & $1.036(1.023-1.048)$ & $<.001$ & $1.036(1.023-1.049)$ & $<.001$ \\
\hline Male gender & $1.057(0.800-1.395)$ & .698 & & \\
\hline Hypertension & $1.102(0.854-1.422)$ & .457 & & \\
\hline History of aortic aneurysm & $1.161(0.761-1.771)$ & .489 & & \\
\hline Connective tissue disease & $0.451(0.312-0.958)$ & .038 & & \\
\hline Diabetes mellitus & $2.283(1.172-4.447)$ & .015 & $2.119(1.083-4.145)$ & .028 \\
\hline History of stroke & $1.339(0.749-2.394)$ & .325 & & \\
\hline Chronic kidney disease & $2.167(1.113-4.219)$ & .023 & $2.134(1.086-4.139)$ & .028 \\
\hline COPD & $2.303(1.532-3.462)$ & $<.001$ & $2.135(1.551-3.233)$ & $<.001$ \\
\hline DeBakey type 1 & $1.193(0.879-1.620)$ & .257 & & \\
\hline Intramural hematoma & $1.139(0.728-1.783)$ & .569 & & \\
\hline Hypotensive shock & $1.363(1.008-1.843)$ & .044 & & \\
\hline Cardiac arrest & $1.544(0.882-2.701)$ & .128 & & \\
\hline Malperfusion & $1.850(1.430-2.393)$ & $<.001$ & $2.011(1.551-2.608)$ & $<.001$ \\
\hline Cardiac & $1.682(1.109-2.550)$ & .014 & $1.885(1.239-2.867)$ & .003 \\
\hline Cerebral & $1.528(0.991-2.354)$ & .055 & $1.520(0.979-2.361)$ & .062 \\
\hline Renal & $1.740(1.074-2.818)$ & .024 & $1.504(0.880-2.526)$ & .138 \\
\hline Gastrointestinal & $1.774(0.940-3.348)$ & .077 & $2.245(1.184-4.257)$ & .013 \\
\hline Peripheral & $1.448(1.063-1.972)$ & .019 & $1.377(0.993-1.909)$ & .055 \\
\hline Spinal & $2.084(1.104-3.932)$ & .023 & $1.820(0.939-3.530)$ & .076 \\
\hline \multicolumn{5}{|l|}{ Penn class } \\
\hline $\mathrm{Aa}$ & reference & & reference & \\
\hline $\mathrm{Ab}$ & $1.564(1.151-2.127)$ & .004 & $1.692(1.241-2.307)$ & .001 \\
\hline Ac & $1.622(1.149-2.289)$ & .006 & $1.462(1.031-2.073)$ & .033 \\
\hline $\mathrm{Abc}$ & $2.471(1.481-4.122)$ & .001 & $2.404(1.437-4.019)$ & .001 \\
\hline \multicolumn{5}{|l|}{ Number of malperfused organs } \\
\hline 1 & $1.808(1.367-2.392)$ & $<.001$ & $1.931(1.456-2.561)$ & $<.001$ \\
\hline 2 & $1.539(0.903-2.625)$ & .113 & $1.773(1.036-3.036)$ & .037 \\
\hline$\geq 3$ & $3.957(2.014-7.775)$ & $<.001$ & $4.815(2.443-9.492)$ & $<.001$ \\
\hline
\end{tabular}

Proximal surgical technique

Supracoronary graft

Supracoronary graft + AVR

Bentall procedure

Distal surgical technique

Ascending aorta

Hemiarch procedure

Arch procedure

$\mathrm{CPB}$ time per minute increment

Crossclamp time per minute increment

Lowest core temperature per ${ }^{\circ} \mathrm{C}$ increment reference

$1.973(1.042-3.737) \quad .037$

$1.072(0.787-1.460)$

.659

\section{reference}

$1.180(0.868-1.604) \quad .290$

$1.580(0.958-2.606) \quad .073$

$1.002(1.000-1.004) \quad .012$

$1.002(1.000-1.005) \quad .046$

1.021 (0.994-1.048)

.127

Values are expressed as hazard ratio ( $95 \%$ confidence interval). Analysis was only performed on 30-day survivors. Any malperfusion, malperfusion per specific organ, Penn classification, and number of malperfused organs were analyzed in separate regression models. COPD, Chronic obstructive pulmonary disease; $A V R$, aortic valve replacement; $C P B$, cardiopulmonary bypass. 
TABLE E6. Missing data

\begin{tabular}{|c|c|c|}
\hline Characteristic & $\begin{array}{l}\text { Missing } \\
\text { cases }(n)\end{array}$ & $\begin{array}{c}\text { Relative missing } \\
\text { rate }(\%)\end{array}$ \\
\hline Age per year increment & 0 & 0 \\
\hline Male gender & 0 & 0 \\
\hline Hypertension & 0 & 0 \\
\hline History of aortic aneurysm & 0 & 0 \\
\hline Connective tissue disease & 0 & 0 \\
\hline Diabetes mellitus & 0 & 0 \\
\hline History of stroke & 0 & 0 \\
\hline Chronic kidney disease & 0 & 0 \\
\hline COPD & 0 & 0 \\
\hline DeBakey type 1 & 0 & 0 \\
\hline Intramural hematoma & 0 & 0 \\
\hline Hypotensive shock & 0 & 0 \\
\hline Cardiac arrest & 0 & 0 \\
\hline Malperfusion & 0 & 0 \\
\hline Cardiac & 0 & 0 \\
\hline Cerebral & 0 & 0 \\
\hline Renal & 0 & 0 \\
\hline Gastrointestinal & 0 & 0 \\
\hline Peripheral & 0 & 0 \\
\hline Spinal & 0 & 0 \\
\hline Penn class & 0 & 0 \\
\hline $\mathrm{Aa}$ & 0 & 0 \\
\hline $\mathrm{Ab}$ & 0 & 0 \\
\hline Ac & 0 & 0 \\
\hline $\mathrm{Abc}$ & 0 & 0 \\
\hline Number of malperfused organs & 0 & 0 \\
\hline 1 & 0 & 0 \\
\hline 2 & 0 & 0 \\
\hline$\geq 3$ & 0 & 0 \\
\hline Proximal surgical technique & 11 & 0.9 \\
\hline Distal surgical technique & 14 & 1.2 \\
\hline CPB time & 99 & 8.5 \\
\hline Crossclamp time & 129 & 11.1 \\
\hline Intraoperative mortality & 0 & 0 \\
\hline 30-d mortality & 3 & 0.3 \\
\hline In-hospital mortality & 3 & 0.3 \\
\hline Perioperative MI & 33 & 2.8 \\
\hline Postoperative stroke & 29 & 2.5 \\
\hline Postoperative coma & 145 & 12.5 \\
\hline RRT & 34 & 2.9 \\
\hline Mesenteric ischemia & 154 & 13.3 \\
\hline Septicemia & 31 & 2.7 \\
\hline DSWI & 31 & 2.7 \\
\hline Acute limb ischemia & 40 & 3.5 \\
\hline
\end{tabular}

TABLE E6. Continued

\begin{tabular}{lcc}
\hline \multicolumn{1}{c}{ Characteristic } & $\begin{array}{c}\text { Missing } \\
\text { cases (n) }\end{array}$ & $\begin{array}{c}\text { Relative missing } \\
\text { rate (\%) }\end{array}$ \\
\hline Surgical treatment of limb ischemia & 172 & 14.8 \\
\hline Ventilatory support $>48 \mathrm{~h}$ & 45 & 3.9 \\
Cardiac tamponade & 31 & 2.7 \\
Reoperation for bleeding & 31 & 2.7 \\
Length of stay in ICU (d) & 313 & 27.0 \\
Late reoperation of the aorta & 26 & 2.2 \\
\hline
\end{tabular}

COPD, Chronic obstructive pulmonary disease; $C P B$, cardiopulmonary bypass; $M I$, myocardial infarction; $R R T$, renal replacement therapy; $D S W I$, deep sternal wound infection; $I C U$, intensive care unit. 